\title{
Anaphylactic shock during elimination diets for severe atopic eczema
}

\author{
T J DAVID
}

Department of Child Health, University of Manchester

SUMMARY Eighty patients with atopic eczema were treated with various elimination diets. Some or all foods were withdrawn then later reintroduced singly to the diet. In four patients reintroduction of a single food (soya, chicken, corn, cows' milk) caused anaphylactic shock. In two patients spontaneous recovery occurred but in two resuscitation and intensive care were required. Anaphylaxis is a definite hazard of these elimination diets. Other than warning the parents, practical precautions are difficult because of the unpredictability of violent reactions and uncertainty about the life saving efficacy of injected adrenaline.

Atopic eczema improves in some children when certain foods are excluded from the diet. ${ }^{1-3}$ The principle is to remove some or all foods from the diet, wait for improvement in the eczema (if it occurs), and then reintroduce foods one by one to identify those which make the eczema worse. In doing this, a situation where anaphylaxis may occur is created.

Anaphylaxis is an immediate hypersensitivity reaction, occurring within a few minutes to hours of antigen challenge, and attributable to the $\operatorname{IgE}$ mediated release of various chemical mediators from appropriate target cells. Three conditions must be met for anaphylaxis to occur: an initial exposure to a sensitising agent, a latent period, and then re-exposure to the agent. ${ }^{4}$ Thus, the elimination of foods followed by their reintroduction in children with allergic diseases can clearly create a potential for anaphylactic reactions.

Although anaphylaxis has been mentioned in passing as a hazard of treatment with elimination diets, ${ }^{5}$ its occurrence has not been properly documented. In the past four years I have treated 80 children suffering from severe atopic eczema with various elimination diets, involving challenge by reintroduction with 1862 food items, an average of 23 food challenges per patient. This report describes four children with atopic eczema in whom anaphylactic shock occurred during treatment with an elimination diet.

\section{Case reports}

Case 1. This boy had severe atopic eczema from the age of 12 months. It affected $90 \%$ of his skin surface area and had failed to respond to conventional topical treatment. He had asthma from the age of 18 months, requiring six hospital admissions by the age of 4 years. There was a history of local urticaria provoked by skin contact with lentils, fish, or nuts. Exposure to cats, dogs, or guinea pigs caused wheezing.

Various elimination diets had been tried without success and the patient was admitted to hospital for trial of a complete exclusion of all normal food and drink. Vivonex (Eaton Laboratories) was used to provide nutrition. After three weeks of Vivonex alone his skin lesions had almost fully cleared and single foods were reintroduced one per week. Eczematous lesions recurred after three days of eating red grapes, but lamb, potato, sweetcorn and a casein hydrolysate cows' milk substitute were introduced without adverse effect and the patient was discharged home. Over the next 15 months, 44 food stuffs were reintroduced at home without adverse reaction. On two separate occasions the ingestion of red grapes, plums, and chicken caused recurrence of eczema after three days of regular consumption. Apart from this his skin was entirely free from lesions.

Fifteen months after hospital discharge soya was deliberately reintroduced in the form of a soya based milk used in the preparation of a blancmange. The patient ate two tablespoons of blancmange and said he liked it. After five minutes he began sneezing, and within ten minutes he was wheezing and coughing. He was given a terbutaline tablet $(2.5$ $\mathrm{mg}$ ) but within 15 minutes of eating the blancmange 
he was completely covered in urticarial weals, he had severe bronchospasm, and his parents rushed him to hospital by car. During the journey he vomited once, his respiration became shallow, cyanosis was observed, and he became unconscious. On arrival he was unconscious, respiratory movements were confined to an occasional gasp with a prolonged expiratory phase and expiratory rhonchi, and he was severely shocked with an impalpable radial pulse. His entire skin surface was covered by urticarial weals $1.5 \mathrm{~cm}$ in diameter, his conjunctivae were very inflamed, and there was periorbital oedema. He was successfully resuscitated, nursed on the intensive care unit, and after 12 hours was fully recovered.

Placing the soya milk on his skin, when accompanied by gentle rubbing, has subsequently been observed to cause florid local urticaria for about 15 minutes. In view of the severity of the anaphylactic reaction a further oral challenge with soya has been avoided.

Case 2. This boy developed periorbital atopic eczema at 4 months of age. Despite conventional topical treatment this increased in severity and by the age of $2 \frac{1}{2}$ years affected about $70 \%$ of his skin surface area. Asthma started at the age of 18 months. There was a history of immediate vomiting after ingestion of cows' milk, and asthma occurring minutes after ingestion of eggs. Various elimination diets had been tried without success, and the patient was admitted to hospital for trial of a complete exclusion of all normal food and drink. Vivonex was given to provide nutrition, but was taken only reluctantly and was stopped after seven days. Comminuted chicken feeds were offered twice, but again were taken reluctantly. On each occasion about 20 minutes after ingesting the chicken he collapsed and became drowsy, limp, and shocked with a poor peripheral circulation; spontaneous recovery occurred after 60 minutes. The comminuted chicken was stopped and the skin improved while the patient received a casein hydrolysate formula for the next 12 days. Single foods were reintroduced one per week. His eczema has remained minimal, though he was able to tolerate only 10 foods in the first year of the diet.

Turkey was introduced without problem at the age of $4 \frac{1}{2}$ years, but three challenges with chicken have resulted in recurrence of eczema within two days.

Case 3. This boy, born at 37 weeks' gestation, was breast fed but also given cows' milk supplements; he developed atopic eczema at 6 weeks of age. This was treated with one per cent hydrocortisone ointment, with little response, and the lesions spread to affect the napkin area, the flexures, and the face. A unilateral cleft lip was repaired at age 3 months. The eczema rapidly worsened so that by 5 months of age it affected the whole face, both arms and legs, and most of the trunk and napkin area. All foods other than the mother's breast milk were excluded from the diet for seven days, with no improvement. Alphalactalbumin and $\beta$-lactoglobulin were, however, discovered in a sample of mother's milk ( $\mathrm{Dr} M \mathrm{R}$ Haeney). The mother's milk supply ceased and the patient was fed on Vivonex for six days with some improvement in the eczema and a slight fall in the eosinophil count $\left(2.23 \times 10^{9} / 1\left(2225 / \mathrm{mm}^{3}\right)\right)$. The patient was then given a casein hydrolysate milk formula, his eczema again improved slightly, and after five days foods were reintroduced one every five days.

By $8 \frac{1}{2}$ months he was on a diet of casein hydrolysate cows' milk substitute, lamb, rice, and carrot but had developed worsening eczema when given banana, rabbit, and potato. Despite this very restricted diet atopic eczema persisted on his face, arms, legs, and trunk. His next food was sweet corn, a teaspoonful being given with his lunch. He disliked it and refused any more. Two minutes after eating the corn he suddenly became very limp, pale, motionless, and unresponsive and his body was covered in urticarial lesions. The parents rushed him to hospital by car, the journey taking 40 minutes. Shortly before arrival his limpness and pallor resolved, and soon after arrival the urticaria improved. No treatment was given. Because of the violence of this reaction further challenges with corn have been avoided.

By the age of 3 years his skin was normal and he was on a diet excluding only corn, eggs, cows' milk, and onion.

Case 4. This boy, the second of dizygotic twins, was born at 37 weeks' gestation. The neonatal period was complicated by hypoglycaemia and by the death of the mother from cerebral haemorrhage. Enlargement of the head led to the discovery of hydrocephalus, and a ventriculoatrial shunt was inserted at age 5 months. Florid napkin eczema developed postoperatively, the rash extending up the abdomen to the umbilicus, and was accompanied by loose stools. He was treated with a cows' milk and milk product free diet, using a soya based formula as a cows' milk substitute. Within a few days the rash and loose stools completely resolved and he remained well on a strict cows' milk and milk product free diet until the age of 12 months, when he was admitted to hospital for a cows' milk challenge. Undiluted, unheated cows' milk $(5 \mathrm{ml})$ was given at $9.15 \mathrm{am}$ and 
Table Investigations undertaken before dietary treatment in four children with anaphylaxis

\begin{tabular}{|c|c|c|c|c|}
\hline & $\begin{array}{l}\text { Case } 1 \\
4 \text { years }\end{array}$ & $\begin{array}{l}\text { Case } 2 \\
21 / 2 \text { years }\end{array}$ & $\begin{array}{l}\text { Case } 3 \\
5 \text { months }\end{array}$ & $\begin{array}{l}\text { Case } 4 \\
12 \text { months }\end{array}$ \\
\hline $\begin{array}{l}\text { Absolute eosinophil count } \\
\left(\times 10^{9} / 1, \quad \mathrm{NV}<0 \cdot 44\right)\end{array}$ & 1.44 & 2.05 & 3.96 & $0 \cdot(06$ \\
\hline Total IgE (IU/ML) & $25000(\mathrm{NV}<62)$ & $1750(\mathrm{NV}<42)$ & $28(\mathrm{NV}<11)$ & $32(\mathrm{NV}<29)$ \\
\hline Anaphylaxis provoked by & Soya & Chicken & Corn & Cows' milk \\
\hline $\begin{array}{l}\text { RAST to the food causing } \\
\text { anaphylaxis }\end{array}$ & Grade 3 positive & $\begin{array}{l}\text { Not tested at } 21 / 2 \text {, but } \\
\text { grade } 3 \text { positive at } 4 \text { years }\end{array}$ & Negative & Negative \\
\hline
\end{tabular}

RAST $=$ radioallergosorbent test; $\mathrm{NV}=$ normal value.

Conversion $-S 1$ to traditional units: eosinophils $1 \times 10^{9} / 1 \approx 1000 / \mathrm{m}^{3}$.

a further $10 \mathrm{ml}$ were given at $10.30 \mathrm{am}$. Thirty $\mathrm{ml}$ were given at $12.30 \mathrm{pm}$, though taken very reluctantly. A full cows' milk feed was offered at 3.30 pm, but he disliked it and most of the feed was refused. $\mathrm{He}$ was asymptomatic at $6 \mathrm{pm}$ and was allowed home.

Soon after arriving home he was noted to be pale, and $10^{1 / 2}$ hours after the challenge he collapsed, vomited once, and was rushed to hospital. On arrival he was profoundly shocked with barely palpable radial and femoral pulses. He was successfully resuscitated, nursed on the intensive care unit, and fully recovered 24 hours after the milk challenge had commenced. At 2 years of age he remains well on a strict cows' milk free diet and his skin is normal.

Details of investigations in all four patients are given in the Table.

\section{Discussion}

The features of anaphylaxis were typical in the first three patients. Spontaneous recovery was fortunate in both cases 2 and 3 , in the former child because the importance of the clinical features was not appreciated at the time and in the latter because of the distance from hospital. Shock is the major clinical feature of anaphylaxis in man, ${ }^{6}$ as happened in cases 2 and 4 . Dislike of the new food was probably a warning in cases 2,3 , and 4 , but not a feature to be relied upon for the first patient enjoyed his soya blancmange. Case 4 was atypical because of the delay of $10^{1 / 2}$ hours between the food challenge and the anaphylactic reaction. I am aware ( $\mathrm{R} \mathrm{D} \mathrm{H}$ Boyd, personal communication) of a similar case. An inpatient cows' milk challenge was performed on a 12 month old baby, who reacted by vomiting so the cows' milk was stopped. Six hours after the challenge he was perfectly well but was found dead in his cot two hours later, just as he was about to be taken home. No abnormalities were found at necropsy.

Of all foods responsible for anaphylaxis, cows' milk is the most commonly reported, though this may simply reflect the frequency of cows' milk allergy. Anaphylaxis shortly after the ingestion of small quantities of milk has been noted in 9 to $33 \%$ of milk sensitive infants. ${ }^{7-9}$ Soya has been previously reported to cause anaphylaxis, ${ }^{10} 11$ though this seems to be rare, unlike the usual features of soya allergy which are well recognised and may be clinically indistinguishable from those of cows' milk allergy. ${ }^{12-14}$ Anaphylaxis due to corn does not seem to be recorded and the dearth of published reports on allergy to corn indicates that this is rare. Allergy to chicken is said to be common, ${ }^{5}$ though anaphylaxis to chicken does not seem to have been described.

Clearly the reintroduction of foods, whether accidental or intentional, in children with eczema on elimination diets, may be associated with anaphylaxis. The rather sparse reports on anaphylaxis from foods in childhood suggests that these events are rare or under reported but local experience implies that anaphylaxis occurs frequently enough to merit consideration when planning the reintroduction of foods in children on elimination diets. Unfortunately, it is impossible to devise any strategy that is fully safe, other than avoiding dietary treatment altogether. We now recommend that very small quantities of food are used on the first occasion a new food is tried, say half a teaspoonful, but there is no rational basis for such a recommendation. Serious anaphylactic reactions can occur with simple skin contact, ${ }^{15}$ or intradermal ${ }^{16}$ or subcutaneous injection ${ }^{16}$ of minute quantities of food. We do warn parents of the possibility of dangerous reactions so that they know to seek immediate medical help, and at the suggestion of the parents in cases 1 and 2 we recommend that food challenges should only be done when both parents are available. While not wishing to discourage other clinicians from using adrenaline, the evidence of its life saving efficacy is weak, ${ }^{617}$ and we have not yet supplied parents with preloaded syringes of adrenaline for home use. Systemic corticosteroids or antihistamines do not 
have an immediate effect in anaphylactic shock and are not suitable alternatives to adrenaline for home use.

Antihistamines given before a food challenge might prevent anaphylaxis but are likely to prevent manifestations of the reaction being sought and are therefore pointless.

The major risk for anaphylaxis has always been thought to be in the first few minutes after ingestion. It has been suggested that 'since severe reactions occur rapidly the patient should be watched for thirty minutes ${ }^{5}$ but experience with case 4 suggests that dangerous reactions may be delayed by many hours. One option would be to insist on all food challenges being done in hospital, keeping the child under observation for 12 hours, but this would be an unrealistic burden for the family and hospital alike. It may be that the high incidence of anaphylaxis in the present series is a chance event and atypical, or possibly reflects selection of very sensitive patients with severe disease. Until further data on the incidence of anaphylaxis are available, it seems better to warn parents of this possibility before embarking on a diet, along with a discussion of the numerous other hazards and difficulties of dietary elimination.

In view of the lack of information about anaphylaxis in children with food allergy I would be glad to receive details of any such cases. I thank Professor R D H Boyd, Dr M R Haeney, and Dr R J Newton for their help and Mrs C Sanders kindly typed the manuscript.

\section{References}

1 Juto P, Engberg S, Winberg J. Treatment of infantile atopic dermatitis with a strict elimination diet. Clin Allergy 1978;8:493-500.
2 Hill DJ, Lynch BC. Elemental diet in the management of severe eczema in childhood. Clin Allergy 1982;12:313-5.

${ }^{3}$ Graham P. Hall-Smith SP. Harris JM, Price ML. A study of hypoallergenic diets and oral sodium cromoglycate in the management of atopic eczema. Br J Dermatol 1984;110:457-67.

4 Richet C. Anaphylaxis. Liverpool: University Press, 1913.

${ }^{5}$ Soothill FJ. Food allergy in childhood. In: Lessof MH, ed. Clinical reactions to food. Chichester: Wiley \& Sons. 1983; 87-101.

${ }^{6}$ Smith PL, Kagey-Sobotka A, Bleecker ER, et al. Physiologic manifestations of human anaphylaxis. Clin Invest Med 1980;66:1072-80.

${ }^{7}$ Goldman AS, Sellars WA, Halpern SR, et al. Milk allergy. I. Oral challenge with milk and isolated milk proteins in allergic children. Pediatrics 1963:32:425-43.

${ }^{8}$ Gryboski JD. Gastrointestinal milk allergy in infants. Pediatrics 1967:40:354-62.

" Walker-Smith JA. Gastrointestinal allergy. Practitioner 1978:220:562-73.

10 Mortimer EZ. Anaphylaxis following ingestion of soybean. $J$ Pediatr 1961;58:90-2.

1 Cotton JB, Couturier P, Grenier JL, Ladreyt JP. Observation d'intolerance isolee au soja, a forme de chocs anaphylactiques. chez un nourrisson. Acta Allergologica 1977;32:217-8.

12 Halpin TC, Byren WJ, Ament ME. Colitis, persistent diarrhea, and soy protein intolerance. J Pediatr 1977;91:404-7.

${ }_{13}$ Powell GK. Milk- and soy-induced enterocolitis of infancy. J Pediatr 1978:93:553-60.

${ }^{14}$ Perkkio M, Savilahti E, Kuitunen P. Morphometric and immunohistochemical study of jejunal biopsies from children with intestinal soy allergy. Eur J Pediatr 1981;137:63-9.

15 Lecks HI. Anaphylaxis from milk protein in diaper ointment. JAMA 1980;244:1560.

16 Austen KF. Systemic anaphylaxis in man. JAMA 1965;192: $116-8$.

17 James LP. Austen KF. Fatal systemic anaphylaxis in man. $N$ Engl J Med 1964;270:597-603.

Correspondence to Dr T J David, Booth Hall Children's Hospital, Charlestown Road, Blackley, Manchester M9 2AA.

Received 26 June 1984 